\title{
Unilateral papular granuloma annulare in a type I diabetic child: a case report and literature review
}

\author{
Aleksandra A. Stefaniak, Jacek C. Szepietowski, Wojciech Baran \\ Department of Dermatology, Venereology and Allergology, Wroclaw Medical University, Poland \\ Adv Dermatol Allergol 2022; XXXIX (3): 637-639 \\ DOI: https://doi.org/10.5114/ada.2021.107547
}

Granuloma annulare (GA) is a fairly common granulomatous disease characterized by painless, erythematous, annular papules with necrobiosis and granuloma formation in histopathology. There are four clinically distinct subtypes: localized, subcutaneous, generalized and perforating. The first two subtypes primarily occur in childhood, particularly in the first 5-6 years of life [1].

An 8-year-old boy was referred to the paediatric dermatology unit due to multiple unilateral skin lesions associated with a moderate itch. The patient's parents reported that the first lesion had appeared 5 years before on the patient's right dorsum of the foot and calf shortly after diabetes mellitus type I diagnosis. A treatment with

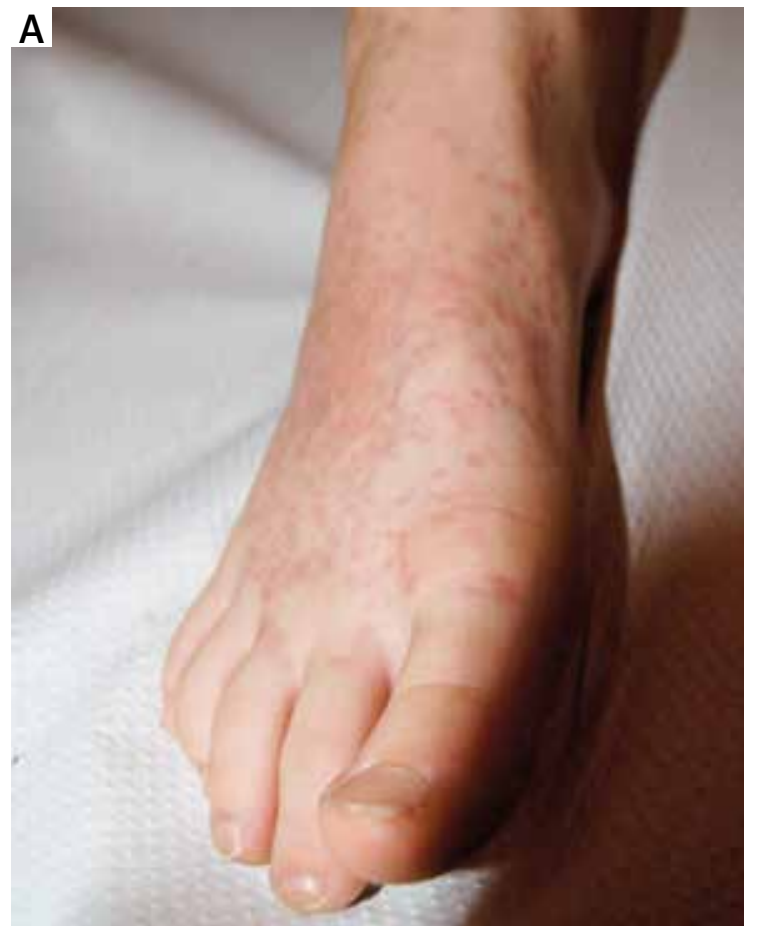

cryotherapy (1 procedure) and mild topical corticosteroids (3 weeks) was partially effective: lesions improved with treatment but did not resolve completely. Besides the diabetes type I diagnosis (T1DM) (diagnosed according to the internationally accepted criteria [2]), the child was otherwise healthy. On admission, physical examination revealed monomorphic papules in the dorsal area of the right foot and spreading to the calf (Figures $1 \mathrm{~A}, \mathrm{~B}$ ). The complete cutaneous inspection did not reveal any other changes on the skin, hair, nail or teeth. Full blood count, routine biochemical analysis and urinalysis were within normal limits, with slightly elevated liver enzymes. Histopathological examination from lesional skin showed

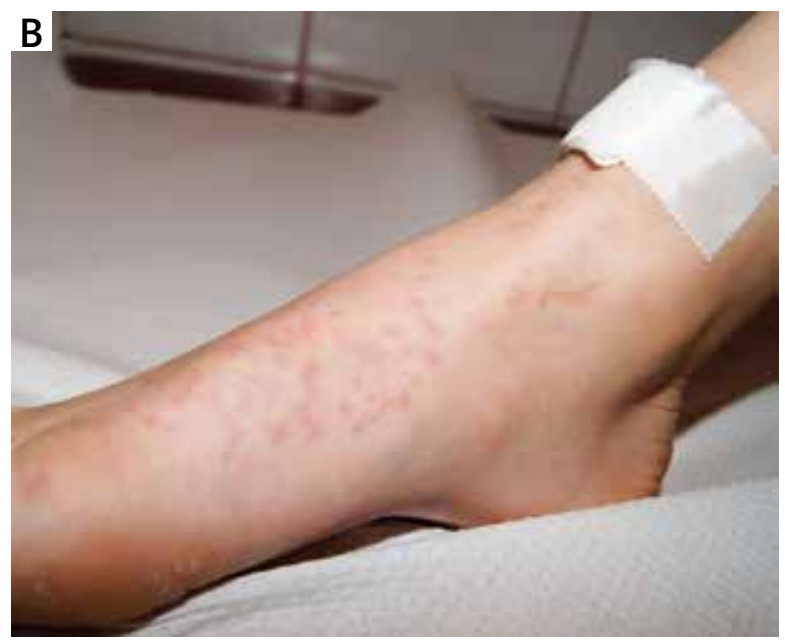

Figure 1. A, B - Multiple papules in the dorsal area of the right foot and spreading to the calf

Address for correspondence: Jacek C. Szepietowski, Department of Dermatology, Venereology and Allergology,

Wroclaw Medical University, 1 Chałubińskiego St, 50-368 Wroclaw, Poland, e-mail: jacek.szepietowski@umed.wroc.pl Received: 9.03.2021, accepted: 25.04.2021. 


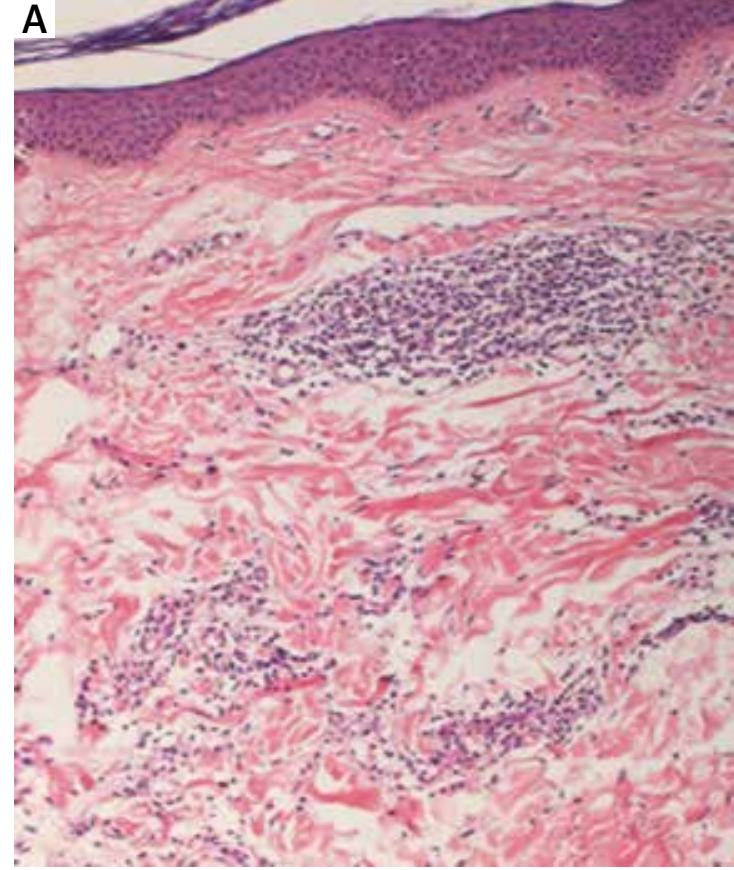

perivascular lymphocytic infiltrate admixed with numerous histiocytes (Figures $2 \mathrm{~A}, \mathrm{~B}$ ).

The clinical presentation of the case described herein is unique in its non-annular morphology and unilateral distribution confined to the right dorsum of the foot and calf. According to the best of our knowledge, this finding of chronic GA located solely on the limb without any additional lesions ever appearing on the torso or any other body part besides the right side of the body has not been reported so far in children. In adults, Borda et al. [3] reported a unilateral GA confined to one leg present for 14 years without generalization to the torso. The patient had concomitant pyoderma gangrenosum and chronic lymphocytic leukaemia [4].

GA has been widely described in adults in association with several systemic diseases, such as viral infections (especially HIV), dyslipidaemia, malignancy (especially hematologic), and thyroid disease [1]. The correlation with diabetes mellitus (DM) in adults is still being discussed [1,4], however, several cases associating GA with diabetes, especially the onset of the latter disease, in children have been reported [5-8]. Spicuzza et al. [7] presented a rare case of an 8-year-old girl with subcutaneous GA as the first sign of T1DM. The lesions appeared 4 months before the T1DM diagnosis, while Agrawal et al. [9] presented a case of subcutaneous granuloma annulare which appeared nearly 3 months before the T1DM diagnosis. Wong and Verbov [10] reported the case of a 3-year-old boy presenting with subcutaneous GA on the scalp skin area, who subsequently developed T1DM only 2 months after the onset of GA. In that case, the clinical picture worsened with poor glycaemic control or

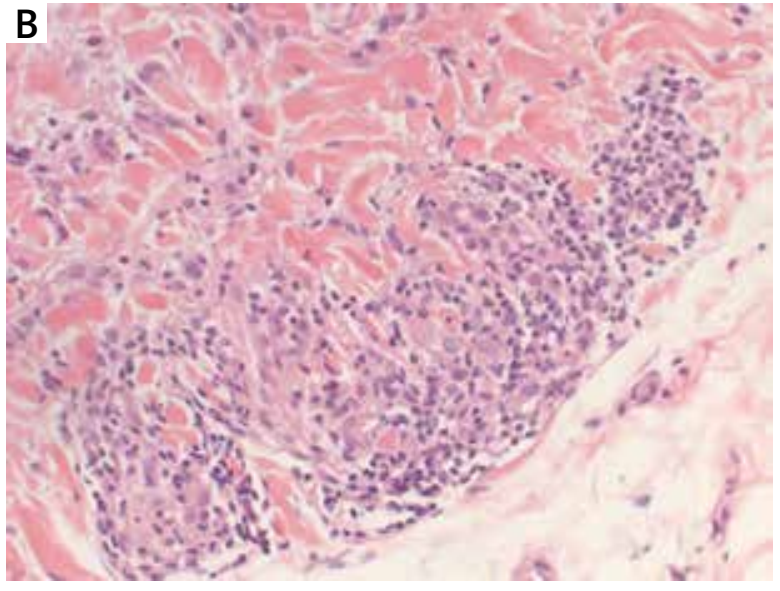

Figure 2. Biopsy from one of the lesions showing an interstitial pattern of GA - intact epidermis, inflammatory perivascular infiltrates in the upper dermis with the presence of lymphohistiocytic cells (H\&E). A -100x; B -200x

intercurrent illnesses. Grogg and Nascimento [11] reported that two of 34 children (5.9\%) with subcutaneous GA were affected by concomitant DM (mean follow-up was 5 years). Kakourou et al. [12] assessed glucose tolerance in a cohort of 15 children with multiple GA and found that these children had higher glycaemic and lower insulinemic parameters compared to matched controls, and that 11 of 15 children had a positive family history of DM. It was speculated that prolonged exposure to high glucose levels may contribute to the expression of GA and collagen alterations have been suggested as a primary event in the process of this skin manifestation. In our case, proper control of T1DM did not affect the course of skin lesions that have slowly spread on the skin within 5 years. Dahl in 2007 [13] presented a report with long-term follow-up of Mayo Clinic records of patients with GA. All patients have had follow-up visits of at least 20 years (with the mean follow-up of 35 years). Three out of 32 (9.4\%) patients have had or have developed T1DM during the follow-up. On the other hand, RapelanoroRabenja et al. [14] assessed thirty children with a localized variant of GA. No association with diabetes mellitus was found, however, the study's follow-up period was not specified. A few years later, in 1998, Martinón-Torres et al. [15] retrospectively assessed 42 children with GA with a follow-up of at least 3 years. Again, diabetes and other potentially related disorders were excluded in all cases. In the end, despite a large number of studies published on GA and DM, definitive evidence for the correlation or association has not been found yet. At least in children, a longer follow-up period seems to reveal the possibility of T1DM diagnosis. 
Treatment options in GA suffer from a lack of large clinical trials. It seems that localized GA may respond to intralesional glucocorticoid, and widespread disease may be initially treated with antimalarial drugs or phototherapy [1]. In our case, 8 weeks of topical mometasone furoate ointment $1 \mathrm{mg} / \mathrm{g}$ was effective and a full remission was achieved. At a 6-month follow-up no recurrence was observed.

In conclusion, both our case and the previous literature reports suggest a possible relationship between the altered glucose metabolism and GA presenting within children population. GA in childhood should prompt the assessment of comorbidities. As DM screening is inexpensive, testing and long-term follow-up of all paediatric patients with GA should be considered. Although the morphological presentation of the GA in the described case is not unusual, the unilateral localization in GA has been sporadically reported; that is why we consider this case report to have practical values for everyday clinical practice.

\section{Conflict of interest}

The authors declare no conflict of interest.

\section{References}

1. Piette EW, Rosenbach M Granuloma annulare: pathogenesis, disease associations and triggers, and therapeutic options. J Am Acad Dermatol 2016; 75: 467-79.

2. American Diabetes Association. 2. Classification and diagnosis of diabetes: standards of medical care in diabetes-2020. Diabetes Care 2020; 43: S14-31.

3. Borda L, Mervis JS, Kirsner RS Unilateral granuloma annulare in association with pyoderma gangrenosum and chronic lymphocytic leukemia. Dermatol Online J 2019; 25: 13030/ qt62c9d1ws.

4. Nebesio CL, Lewis C, Chuang TY. Lack of an association between granuloma annulare and type 2 diabetes mellitus. Br J Dermatol 2002; 146: 122-4.

5. Sehgal VN, Bhattacharya SN, Verma P. Juvenile, insulin-dependent diabetes mellitus, type 1-related dermatoses. J Eur Acad Dermatology Venereol 2011; 25: 625-36.

6. Erkek E, Karaduman A, Gül BE, et al. An unusual form of generalized granuloma annulare in a patient insulin-dependent diabetes mellitus. Acta Derm Venereol 2001; 81: 48-50.

7. Spicuzza L, Salafia S, Capizzi A, et al. Granuloma annulare as first clinical manifestation of diabetes mellitus in children: a case report. Diabetes Res Clin Pract 2012; 95: e55-7.

8. Akyürek N, Atabek ME, Eklioglu BS, Tol H. A rare case of granuloma annulare in a 6-year-old child with type 1 diabetes. J Pediatr Endocrinol Metab 2013; 26: 811-2.

9. Agrawal AK, Kammen BF, Guo H, Donthineni R. An unusual presentation of subcutaneous granuloma annulare in association with juvenile-onset diabetes: case report and literature review. Pediatr Dermatol 2012; 29: 202-5.

10. Wong GA, Verbov JL. Subcutaneous granuloma annulare of the scalp in a diabetic child. Pediatr Dermatol 2002; 19: 276-7.
11. Grogg KL, Nascimento AG. Subcutaneous granuloma annulare in childhood: clinicopathologic features in 34 cases. Pediatrics 2001; 107: E42.

12. Kakourou T, Psychou F, Voutetakis A, et al. Low serum insulin values in children with multiple lesions of granuloma annulare: a prospective study. J Eur Acad Dermatology Venereol 2005; 19: 30-4.

13. Dahl MV. Granuloma annulare: long-term follow-up. Arch Dermatol 2007; 143: 946-7.

14. Rapelanoro-Rabenja F, Maleville J, Taïeb A. Granulome annulaire localisé chez l'enfant: évolution de 30 cas. Arch Pediatr 1995; 2: 1145-8.

15. Martinon-Torres F, Martinon-Sanchez JM, Martinon-Sanchez F. Localized granuloma annulare in children: a review of 42 cases. Eur J Pediatr 1999; 158: 866. 